\title{
On Risk Management of Injuries in Physical Education
}

\author{
Junchao Bao \\ Dept. of PE, Wuhan University of science and technology, Wuhan, Hubei 430081, China.
}

Keywords: Risk management; injury accident, social resilience; physical education.

\begin{abstract}
By explaining the risk management process of teachers to physical education injury accidents: risk identification, risk assessment and risk response, This paper discusses three factors that affect the risk management of sports teaching injury: the risk bearer and the risk beneficiary are different, the accident handling principle is not conducive to the risk management, and the risk assumption is single. The author puts forward the direction of socialized development of risk assumption and the mechanism construction of social resilience.
\end{abstract}

\section{Introduction}

Risk management refers to the scientific management method that economic units can predict, identify, evaluate, and analyze the risks they may encounter, and on this basis effectively handle risks to achieve maximum safety and security at the lowest cost [1]. Including risk management objectives, risk identification, risk assessment, risk response, and risk monitoring and other five links. Risk identification is the basis of risk assessment, and risk assessment is the precondition of risk response [2]. The risk management of injury accidents in physical education has attracted wide attention.

\section{The Risk Management Process of Teachers' Physical Education}

\subsection{Risk Identification.}

The open character of physical education teaching environment determines that the risks it faces are constantly changing. There are various factors that lead to risk in Teachers' decision-making. Risk sources refer to those sources or conditions that may lead to risk consequences [3]. Risk managers must have keen vision and professional spirit to capture constantly changing and emerging risk sources and maintain the dynamic nature of risk identification. The sources of risk in physical education generally include: natural environment, teaching environment, cognitive environment, unexpected environment (abrupt change of environment), random environment, etc. The abnormal changes in the weather, the quality and maintenance of the field and equipment, the professional knowledge and skills of the teachers, the ability to observe, the judgment and the strain, and the antagonism of the sports competition are all possible sources of risk.

\subsection{Risk Assessment.}

To evaluate the risk of injury accidents in physical education, human factors, environmental factors, organization and management factors are mainly considered. Human factors include the number of students, sports ability, basic equipment, basic quality and self-consciousness, teachers' qualifications, understanding of students, professional quality, teachers' observation, analysis, and ability to solve problems. The environmental factors include the integrity of the site, the equipment, the hidden danger of safety, the full space of sports activities, and the possibility of the invasion of other personnel and equipment, etc. The organizational management factors are the organization control of the class, the effective control and organization of students' reasonable interaction between teaching and learning. Risk assessment is the prediction of the possibility of risk and the seriousness of the risk outcome. The magnitude of risk is judged by the seriousness of risk consequences. The evaluation results are the main basis for the selection of risk response measures. It is the professional reaction of the PE teachers. 


\subsection{Risk Response.}

The risk management measures are optimized and combined to achieve the best risk management effect at a minimum cost [5]. Teachers generally use risk avoidance, risk transfer, loss control, risk retention and other coping styles.

First, Risk avoidance. Eliminating risks completely and passively will not yield any benefits at the same time. Risk avoidance is usually applied to high risk events, and risk is avoided by abandoning or changing decisions. The cancellation of high-risk sports is to take into account that the consequences are very serious once an injury occurs.

Second, Risk transfer. Risk transfer does not eliminate or reduce risk, but it can effectively reduce the risk pressure of risk managers. The risk transfer in physical education is mainly for students to buy sports injury accident insurance, thereby reducing the risk pressure of teachers. Risk transfer is the most important choice for risk management of injury accidents in physical education.

Third, Loss control. First, it refers to the root of the loss before the loss occurs, the probability of reducing the loss event, and the two is to reduce the extent of the loss after the occurrence of the risk event. The way of loss control is to divide, reserve and draw up relevant documents. This method is generally adopted in physical education teaching after the occurrence of common low risk prevention and risk events.

Fourth, the risk is reserved. The risk of retention is often low, which is a common way of injury accidents in physical education. If a variety of contingency plans are formulated, an emergency response plan after the occurrence of a risk event is a positive risk retention strategy.

\section{The Influencing Factors of Accident Risk Management in Physical Education}

\subsection{Physical Education Injury Accident Risk Bearers Are Different from Beneficiaries.}

Whoever risks, who benefits. The difference between the undertaker and the beneficiaries of injury risk in physical education will inevitably lead to a negative attitude towards risk management by risk managers. The disunity of thinking and educational ideas of risk management subjects, such as teachers, schools and educational departments, also has an important impact on risk management and normal teaching activities.

\subsection{The Principle of Dealing With Injuries in Physical Education Is Not Conducive to Risk Management.}

Anyone who is responsible for the injury accident in physical education should compensate the injured person in the form of economy. The principle of imputation is the core issue of dealing with injury accidents in physical education. It is the basis and standard [6] for determining the civil liability of the perpetrator. The principles of imputation applicable to injury accidents in physical education include fault liability principle, fault presumption principle, fair liability principle and so on. [7] These attribution principles make the risk bearing main body of physical education teaching injury faced with severe challenges. In particular, teachers' risk bearing capacity is very low, even the principle of fair liability will bring disastrous consequences. Therefore, it is difficult for teachers to carry out positive and effective risk management.

\subsection{Physical Education Injury Accident Risk Bearing the Main Body Is Single.}

From the perspective of state and social development, education is the hope of a nation and the future of a nation. It is a social undertaking whose main body of interest is the whole country and the whole society. In line with the principle of "who takes risks and benefits", the risk of education should be shared by the whole society. The risk bearer should not only include teachers, schools, education departments, but also students, parents, and the whole society can effectively improve the risk resistance. 


\section{Reflections on Risk Management of Injuries in Physical Education}

\subsection{The Socialization Direction of the Subject of Unimpeded Risk Undertaking.}

The socialized development of the risk bearer is conducive to changing the teacher's risk management concept of abnormality risk, alleviating the teacher's risk pressure, reducing its moral hazard, and relieving it from the unbearable risk pressure, and focusing on the exploration and experiment of teaching reform and innovation. So that the education department can concentrate more on the exploration and innovation of educational laws and educational management. It has strategic significance for the healthy development of the whole education.

\subsection{Improved Social Resilience.}

To achieve the socialized transformation of the main body of educational risk bearing, we must enhance social resilience. Improving the ability to resist the risk of sports injuries includes improving the social resistance of students, families, teachers, educational organizations, government and other main bodies, as well as the system construction of corresponding operation mechanism and guarantee. First, we should strengthen safety education and enhance teachers' professional ethics. Second, improving the socialized channel of risk transfer is one of the most important ways to change the concept of teacher risk management. Third, improve the legislation of sports injury accidents.

\section{References}

[1]. Baker, S., Punish, Dandy Smith, Techniques for the Analysis of Risks in Major Projects[J].Operational Research society, 1998, 49:567-572.

[2]. Yang Yawing, Qi Anhui. Study on risk management in the process of organization of school physical education [J]. Journal of Xi'an Physical Education University, 2005, 22 (5): 84-87.

[3]. Wang Xiaoqun. Risk management [M]. Shanghai: Shanghai University of Finance and Economics press, 2003.

[4]. Feng Linen. Decision making risk management modeling and applied research [D]. Tianjin University, 2006.

[5]. Wang Liming. Tort law of civil law [M]. Beijing: Renmin University of China press, 1995:81-85.

[6]. Han Yong. Review and Prospect of Chinese Sports Law: a survey of problem oriented research [J]. Journal of Tianjin University of Sport, 2008, 23 (4): 320-327.

[7]. Zhang Xuan. Social resilience: New Thoughts on risk management theory [EB/OL]. http://theory.people.com.cn/GB/49154/49156/8777583.html, 2009-02-22.

[8]. Zhang Dachau, Li Min. Theoretical research on sports risk management system in foreign countries [J]. Sports science, 2009, (29) 7:43-54. 